\title{
Astragalus in the Prevention of Upper Respiratory Tract Infection in Children with Nephrotic Syndrome: Evidence-Based Clinical Practice
}

\author{
Chuan Zou, Guobin Su, Yuchi Wu, Fuhua Lu, Wei Mao, and Xusheng Liu \\ Nephrology Center, Guangdong Provincial Hospital of Chinese Medicine, No. 111 Dade Road, Guangzhou, \\ Guangdong Province 510120, China \\ Correspondence should be addressed to Xusheng Liu; xushengliu801@126.com
}

Received 30 October 2012; Revised 18 February 2013; Accepted 25 February 2013

Academic Editor: Taixiang Wu

Copyright (C) 2013 Chuan Zou et al. This is an open access article distributed under the Creative Commons Attribution License, which permits unrestricted use, distribution, and reproduction in any medium, provided the original work is properly cited.

\begin{abstract}
Aims. To explore whether Astragalus or its formulations could prevent upper respiratory infection in children with nephrotic syndrome and how best to use it. Methods. We transformed a common clinical question in practice to an answerable question according to the PICO principle. Databases, including the Cochrane Library (Issue 5, 2012), PUBMED (1966-2012.8), CBM (19782012.8), VIP (1989-2012.8), and CNKI (1979-2012.8), were searched to identify Cochrane systematic reviews and clinical trials. Then, the quality of and recommendations from the clinical evidence were evaluated using the GRADEpro software. Results. The search yielded 537 papers. Only two studies with high validity were included for synthesis calculations. The results showed that Astragalus granules could effectively reduce URTI in children with nephrotic syndrome compared with prednisone treatment alone ( $23.9 \%$ versus $42.9 \% ; \mathrm{RR}=0.56$ and $95 \% \mathrm{CI}=0.33-0.93$ ). The dose of Astragalus granules was 2.25 gram (equivalent to 15 gram crude Astragalus) twice per day, at least for 3-6 months. The level of evidence quality was low, but we still recommended the evidence to the patient according to GRADEpro with the opinion of the expert. Followup showed the incidence of URTI in this child decreased significantly. Conclusions. Astragalus granules may reduce the incidence of URTI in children with nephrotic syndrome.
\end{abstract}

\section{Background}

Infection is one of the most common complications in children with nephrotic syndrome (NS). The annual incidence of invasive bacterial infection based on retrospective case series was shown to be about $1-2 \%$, and the cumulative risk for the 10 -year susceptibility period was around $10-20 \%$ [1].

In China, the incidence of nosocomial infection has been reported to be as high as $34-79 \%$ in children with nephrosis [2-4] and 22\% in adults [5]. The most commonly reported infection accompanying nephrotic syndrome was upper respiratory infection (8.8-29.27\%) [6-8]. Most of these infections were closely associated with frequent relapses in children with nephrosis [9], especially viral upper respiratory tract infections (URTI) $[10,11]$, which resulted in significant admission rates and healthcare costs.

There are several interpretations of this high risk of infection in NS, including urinary losses of factors B and D of the alternative complement pathway, impaired polymorph phagocytic function, edema, and secondary effects of corticosteroids and cytotoxic therapy $[12,13]$. Efforts have been made to develop effective interventions dealing with this problem globally. To date, various prophylactic interventions have been used and/or recommended for reducing the risk of infection in nephrotic patients in clinical practice. These include chemoprophylaxis with antibiotics, pneumococcal vaccines, and immunoglobulin replacement therapies $[1,13]$. However, the effectiveness of these prophylactic therapies has not been confirmed, and these treatments are quite expensive and still have some adverse effects [14].

The Chinese herbal medicine has been used to address infections for thousands of years. One representative medicine, Astragalus (Huangqi), has been the most studied. Many studies have reported that Astragalus or its formulations could prevent upper respiratory infection in immunocompromised patients $[15,16]$. 


\section{Clinical Question}

An 11-year-old boy was referred to Professor Huang Chunlin's renal clinic because of repeated relapses of nephrotic syndrome. Nine years earlier, he had been diagnosed with primary nephrotic syndrome after the onset of limb edema. Prednisone at a dose of $60 \mathrm{mg} /$ day was given and gradually withdrawn when complete remission was achieved after 1 month. However, he suffered his first relapse of nephrotic syndrome when he was on a prednisone dose of $15 \mathrm{mg} /$ day due to an upper respiratory tract infection. Although the infection was controlled quickly, his nephrotic syndrome was not alleviated, forcing him to take the initial dose of prednisone ( $60 \mathrm{mg} /$ day) again. Another complete remission was then achieved. In the subsequent 9 years, he experienced a total of eight relapses whenever the prednisone dose was reduced to lower than $20 \mathrm{mg}$ /day. In particular in the last year, URTI occurred eight times, and NS relapsed three times, apparently triggered by URTI. Three months before this referral, he started taking prednisone at a dose of $60 \mathrm{mg} /$ day for the same clinical situation described above, and it had been tapered gradually to $20 \mathrm{mg}$ at the time of the visit. At that time, he presented with what appeared to be Cushing's syndrome: flushed face, moon face, buffalo hump, and complaining of feeling fatigued and sweaty. Physical examination showed congestion of the throat with swelling of the bilateral tonsils and purple striae all over the body, but no edema of the lower limbs. Laboratory investigations showed the following: $24 \mathrm{~h}$ urinary protein was in the normal range, serum immunoglobulin (IgG) slightly low, serum albumin $38 \mathrm{~g} / \mathrm{L}$, and serum creatinine $45 \mu \mathrm{mol} / \mathrm{L}$. Kidney ultrasonography showed no abnormality.

His mother had heard about Astragalus (Huangqi), a Chinese herb, which has effects in strengthening immunological function and preventing respiratory tract infection. She inquired about the effects and application of Astragalus for her son's situation.

The common clinical question was whether it would be effective to use Astragalus to prevent upper respiratory infection in children with nephrotic syndrome. What would be the expected effects and the preferred route of application (dose, course of treatment)?

The PICO question was formulated as follows: in patients or a population with primary nephrotic syndrome, were Astragalus formulations (as sole agents or in combination with other drug regimens) of value compared with a placebo or conventional treatment of NS in effectively preventing upper respiratory tract infections?

Thus,

P: children with primary nephrotic syndrome,

I: Huangqi or Astragalus formulations (either as sole agents or in combination with other drug regimens),

C: conventional treatment alone,

O: upper respiratory infection rate.

\section{Search for Evidence}

3.1. Inclusion Criteria. All randomized controlled trials (RCTs) evaluating the use of Huangqi or Astragalus as sole agents or in combination with other drug regimens compared with other drugs in preventing URTI in children (0-18 years of age) with primary NS were included. There was no restriction on population characteristics, language, or publication type. The primary outcomes were the incidence of URTI and adverse events. Duplicate publications reporting the same groups of participants were excluded.

3.2. Search Methods for Identification of Studies. We designed a search filter restricted to articles relevant to the PICO question within PUBMED from (1966-2012.8), Embase.com (1980-2012.8), Cochrane Library (Issue 5, 2012), The Chinese Biomedicine Database (CBM from 1978-2012.8), WeiPu Chinese Scientific Magazine Database (VIP; 1989-2012.8), and China National Knowledge Infrastructure (CNKI; 19792012.8).

The search used a combination of search terms using relevant synonyms for the domain: "kidney diseases," "glomerulonephritis," "nephrosis," "minimal change nephropathy," "nephropathy," "Huangqi", "Astragalus membranaceus," "Astragalus," "respiratory tract infection," and "upper respiratory infection." The search was limited to clinical trials and Cochrane systematic reviews. We first tried to construct search strategies using PICO. However, the results were limited, and not all were relevant. Thus, we modified our search strategies using only PI to cover most relevant studies.

The titles and abstracts of all published articles obtained from these search strategies were examined to determine whether they were applicable to the purpose of this study.

3.3. Data Collection. Titles and abstracts from the preliminary search results were checked independently by two authors (Chuan Zou and GuoBin Su) to identify clearly irrelevant studies that needed to be discarded. Full texts of the remaining studies were evaluated to judge whether the inclusion criteria were met. If information on key points was unclear, the relevant original authors of the articles were contacted by telephone for clarification.

3.4. Data Extraction. Data extraction was conducted on fulltext copies of all included trials using a data extraction form designed for the purpose. Data regarding the characteristics of the study, including the sample size, age, disease period, and clinical features of the children with NS, were gathered. The types and doses of different Huangqi formulations, followup time, side effects, and primary outcomes were independently abstracted from the remaining articles by two authors (Chuan Zou and GuoBin Su). Disagreements were resolved by discussion and consensus, mediated by a third author (XuSheng Liu).

3.5. Quality Assessment. The risk of bias in individual studies was assessed by the GRADE approach across five aspects: sequence generation, allocation concealment, blinding, incomplete outcome data, selective outcome reporting, 
TABLE 1: Search strategies.

\begin{tabular}{|c|c|c|}
\hline Database & Searching strategies & Hits \\
\hline PubMed (1966 2012.8) & 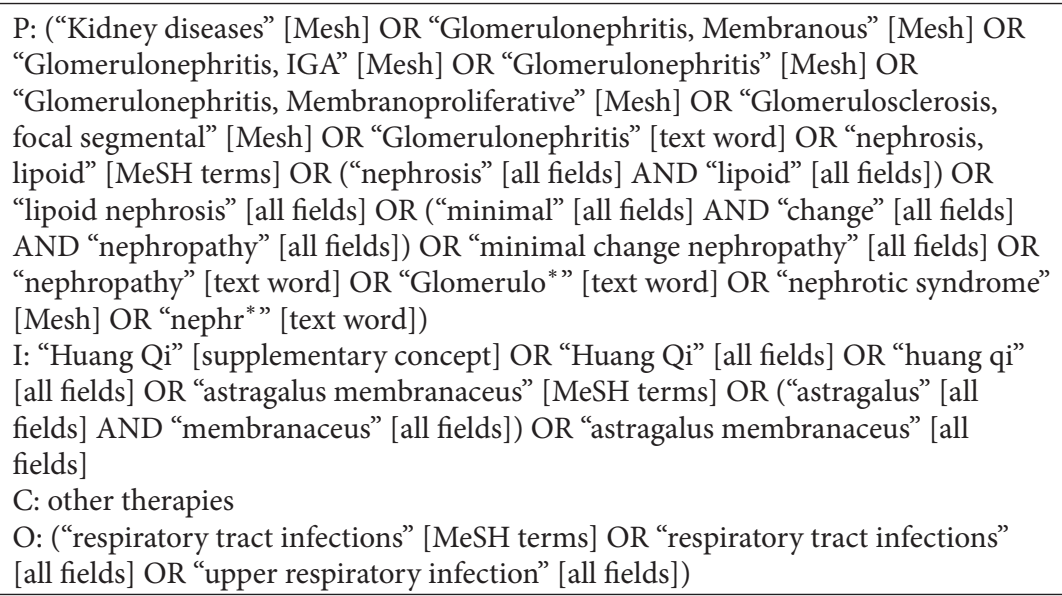 & $\begin{array}{l}P+I=59 \\
P+I \text { Filters: } \\
\text { Humans }=24 \\
P+I+O=0\end{array}$ \\
\hline EMBASE (1974 2012.8) & 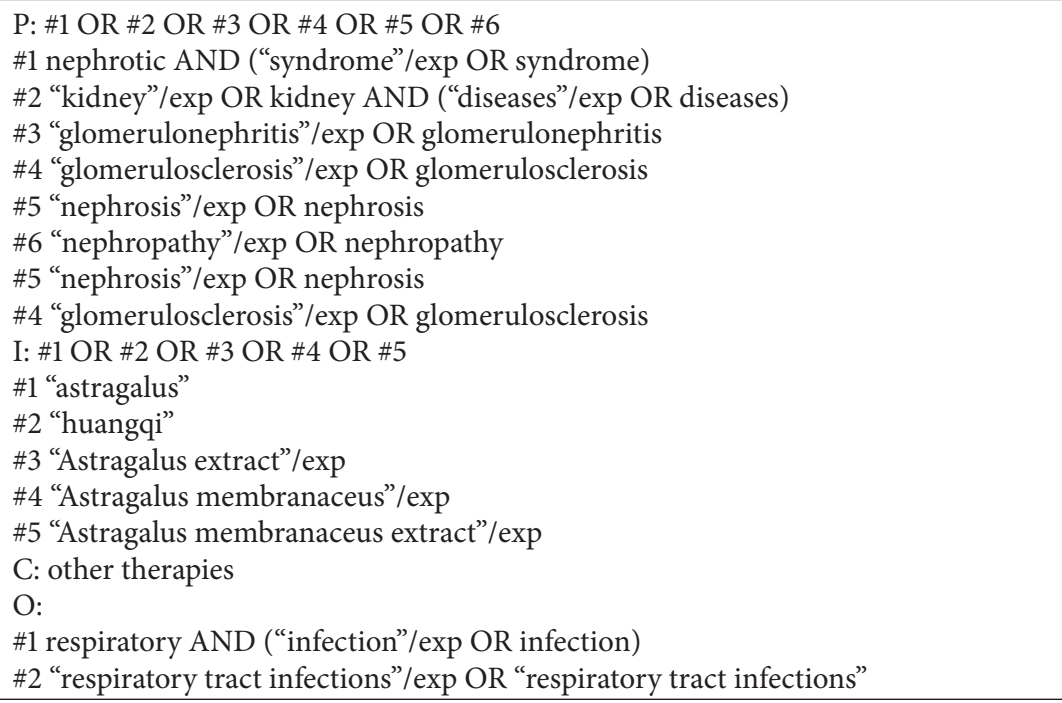 & $\begin{array}{l}\mathrm{P}+\mathrm{I}=266 \\
\text { Limited } \\
\text { human } 120 \\
\mathrm{P}+\mathrm{I}+\mathrm{O}=17\end{array}$ \\
\hline Cochrane Library (Issue 5, 2012) & $\begin{array}{l}\text { Searching field: title, abstract, or keywords } \\
\text { P: "Kidney diseases" OR "Membranous Glomerulonephritis" OR } \\
\text { "Glomerulonephritis" OR "lipoid nephrosis" OR "minimal change nephropathy" } \\
\text { OR "minimal change disease" OR "nephrotic syndrome" OR"nephr" } \\
\text { I: "Huang Qi" OR "astragalus membranaceus" } \\
\text { C: other therapies } \\
\text { O: ("respiratory tract infections" OR "respiratory tract infections" OR "upper } \\
\text { respiratory infection") }\end{array}$ & $\begin{array}{l}P: 37 \\
P+I=3\end{array}$ \\
\hline CBM (1978 2012.8) & Subject or title or abstract: Nephritic syndrome AND respiratory infection & 30 \\
\hline CNKI (1979 2012.8) & Subject or title or abstract: Nephritic syndrome AND respiratory infection & 301 \\
\hline VIP (1989 2012.8) & Title or keyword: Nephritic syndrome AND respiratory infection & 25 \\
\hline
\end{tabular}

* Refers to searching for all terms that begin with a word, enter the word followed by an asterisk $\left({ }^{*}\right)$.

and other potential biases. The GRADE approach was used to evaluate the quality of evidence, and the results are presented in the Summary of Findings table. The quality rating for studies assessed using the GRADE approach has four levels: high, moderate, low, or very low.

3.6. Data Analysis. Relative risk was calculated with the GRADEProfiler 3.2.2 (GRADE Working Group 2004-2007) and is shown in the GRADE Quality Assessments tables.
A process was designed to combine data across studies to perform a meta-analysis when Huangqi or Astragalus was studied as the sole constituent or in combination with other regimens, regardless of the form of the agents (liquid, powder, granule, or pill). If the main effects of the whole compound in the studies were similar, data were combined. The fixed-effect mode was used to combine dichotomous data if homogeneity was found. If heterogeneity was found, the random-effect mode was used. 


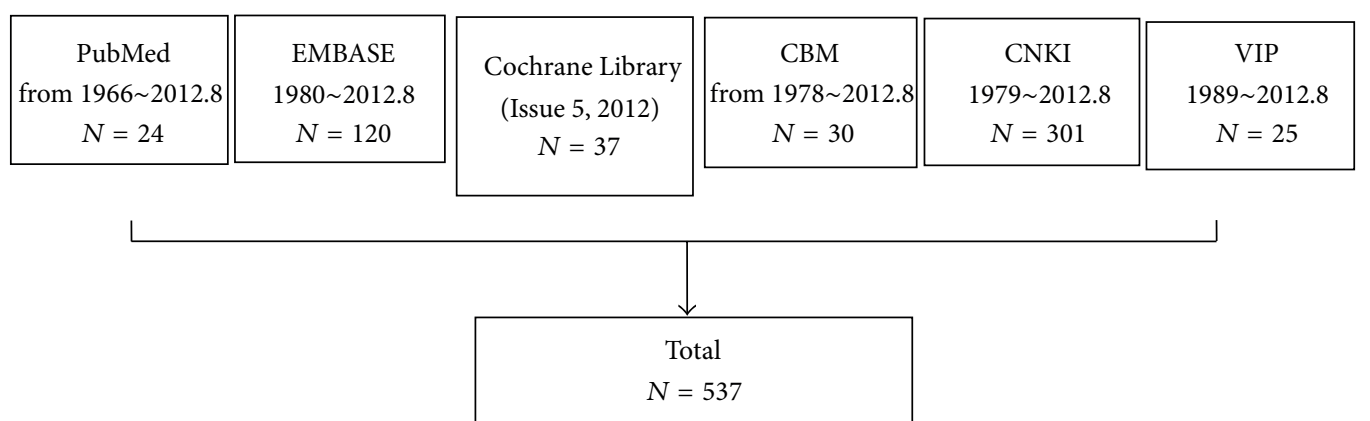

Title and abstract screening

Studies excluded $(N=438)$ :

Animal experiments $(N=61)$

Secondary nephritic (syndrome: SLE, HBV

associated nephritis, diabetic nephropathy, etc.)

$(N=204)$

Nursing studies $(N=60)$

Comments or letters $(N=28)$

Duplicates removed $(N=85)$

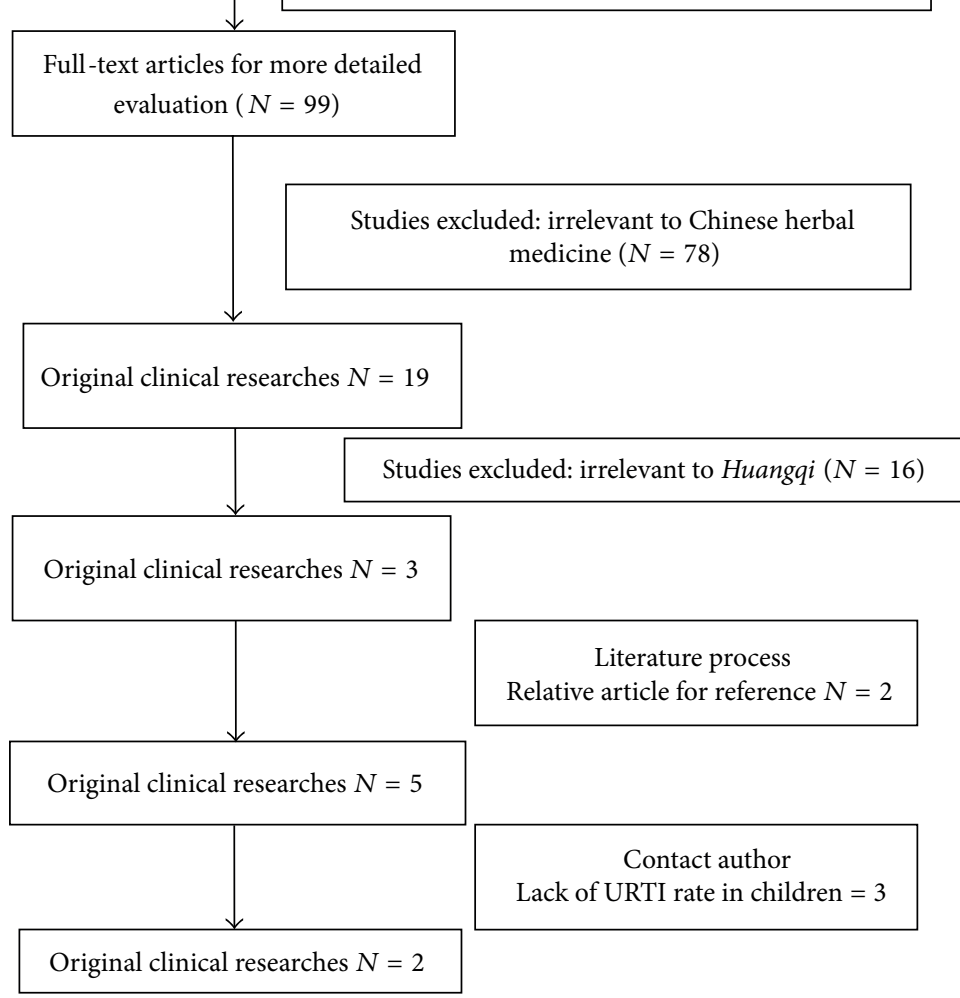

FIGURE 1: Search process: flow diagram of included and excluded studies. A search for relevant studies was performed using the PubMed database, Embase, Cochrane library, CNKI, CBM, and VIP subsequently filtered out based on the inclusion/exclusion described.

\section{Results of Search for Evidence}

4.1. Search Result. Our search yielded 24 articles in PubMed, 120 in Embase.com, 37 in Cochrane Library, 30 in CBM, 301 in CNKI, and 25 in VIP (for search strategies, see Table 1). Upon screening, five original clinical research articles [17-21] and two Cochrane systematic reviews $[14,16]$ remained for further analysis (for search and screening process, see flow chart, Figure 1).

Yuan et al. 2004 [21] compared Huangqi and Hongzao (red Chinese date) with placebo $(n=60)$ in children and adults (aged 8-60 years old). The study only included patients 
TABLE 2: Characteristics of the included studies.

\begin{tabular}{|c|c|c|c|c|c|c|c|c|}
\hline & Study design & Population & Intervention & Comparison & Duration & Outcome & Followup & $\begin{array}{l}\text { Adverse } \\
\text { reaction }\end{array}$ \\
\hline $\begin{array}{l}\text { Kang, } 2005 \\
{[17]}\end{array}$ & $\begin{array}{l}\text { Parallel RCT } \\
N=38\end{array}$ & $\begin{array}{l}\text { Age } \\
\text { I: } 1.5 \text { to } 6 y \\
\text { C: } 1.8 \text { to } 7 y\end{array}$ & $\begin{array}{l}\text { STD prednisone }+ \\
\text { Huangqi (Astragalus) } \\
\text { granules } \\
\text { Dose: } 15 \text { g b.i.d.p.o. }\end{array}$ & $\begin{array}{c}\text { STD } \\
\text { prednisone }\end{array}$ & $\begin{array}{l}3 \text { to } 6 \\
\text { months }\end{array}$ & $\begin{array}{l}\text { Infection } \\
\text { (I: 14/22, C: 15/16) } \\
\text { URTI } \\
\text { (I: 8/22, C: } 9 / 16) \\
\text { Relapse } \\
\text { (I: } 10 / 22, \text { C: } 13 / 16) \\
\end{array}$ & $\begin{array}{c}\text { Not } \\
\text { mentioned }\end{array}$ & NS \\
\hline $\begin{array}{l}\text { J. Chen and } \\
\text { S. Q. Chen, } \\
2008 \text { [18] }\end{array}$ & $\begin{array}{l}\text { Parallel RCT } \\
N=92\end{array}$ & $\begin{array}{l}\text { Age } \\
\text { I: } 2.0 \text { to } 13.2 \mathrm{y} \\
\text { C: } 2.1 \text { to } 13.7 \mathrm{y}\end{array}$ & $\begin{array}{l}\text { STD prednisone }+ \\
\text { Huangqi (Astragalus) } \\
\text { granules (oral) } \\
\text { Dose: } 7.5 \mathrm{~g} \text { bid ( }<3 \\
\text { years); } 10 \mathrm{~g} \text { bid ( } 3 \text { to } 6 \\
\text { years); } 15 \text { g bid ( }>6 \text { years) }\end{array}$ & $\begin{array}{l}\text { STD } \\
\text { prednisone }\end{array}$ & 3 months & $\begin{array}{l}\text { Infection } \\
\text { (I: 14/45, C: 28/47) } \\
\text { URTI } \\
\text { (I: 8/45, C: 18/47) } \\
\text { Relapse } \\
\text { (I: 9/45, C: } 23 / 47)\end{array}$ & 8 months & NS \\
\hline
\end{tabular}

STD prednisone: initial dose $1 \mathrm{mg} / \mathrm{kg} / \mathrm{d}$ for 8-12 weeks. Every other day for 6 months. When urine protein is negative, decreased $5 \mathrm{mg} / \mathrm{wk}$ until reduced dose tapered gradually to $0.4 \mathrm{mg} / \mathrm{kg} / \mathrm{d}$ over 6 months and maintained at this dose for $12-18$ months. Finally, tapered gradually until withdrawal to $0.5 \mathrm{mg} / \mathrm{kg} / \mathrm{d}$, then $1 \mathrm{mg} / \mathrm{kg}$ every other day for 6 months.

STD prednisone + CTX: initial prednisone dose $1 \mathrm{mg} / \mathrm{kg} / \mathrm{d}$ plus CTX $50 \mathrm{mg}$ b.i.d.p.o. (total in $8 \mathrm{mg}$ ).

URTI: upper respiratory tubular infection; I: intervention; C: comparision.

TABLE 3: Characteristics of the included Cochrane reviews.

\begin{tabular}{|c|c|c|c|c|}
\hline & Intervention & Comparision & Number of RCTs & Participants \\
\hline Wu et al., 2012 [14] & $\begin{array}{l}\text { IVIG, thymosin, OTF, } \\
\text { MPT, BCG, Lantigen } \\
\text { B, TIAOJINING, } \\
\text { Huangqi granules + } \\
\text { baseline treatment }\end{array}$ & Baseline treatment & 12 & 762 \\
\hline Yuan et al., 2008 [16] & $\begin{array}{l}\text { Huangqi injection, } \\
\text { Huangqi and red } \\
\text { Chinese, Huangqi and } \\
\text { Danggui + baseline } \\
\text { treatment date }\end{array}$ & Baseline treatment & 3 & 128 \\
\hline
\end{tabular}

IVIG: intravenous immunoglobulin; OTF: oral transfer factor; MPT: mannan peptide tablet; BCG: Bacillus Calmette-Guerin (BCG) vaccine injection; and baseline treatment: STD prednisone.

with refractory nephrotic syndrome (mesangial proliferative glomerulonephritis). The paper did not describe the baseline decline in renal function in the patients. The control group received prednisone treatment alone. The experimental group received Huangqi and Hongzao in addition to the drugs the control group received. The study showed that, compared with placebo, the Astragalus formulation (with Hongzao) significantly reduced the occurrence of respiratory tract infection (RR 0.27, 95\% CI $=0.08-0.88$ ) [16].

Astragalus granules significantly reduced the number of nosocomial infections or unspecified infections in children with nephrotic syndrome (two studies [17, 18], 130 participants: RR $0.62,95 \% \mathrm{CI}=0.47-0.83 ; P=0.001, I^{2}=0 \%$ ) [14] and in adults (J. Zhang and Y. Zhang 2008 [20], RR 0.55). However, these studies did not report the specific respiratory tract infection rate.

Xie and Peng 2010 [19] compared standard prednisone treatment + Huangqi extract (by boiling Huangqi (Astragalus) $700 \mathrm{~g}$ with water $5600 \mathrm{~g}$ three times, $90 \mathrm{~min}$ each, and concentrating the solution to $700 \mathrm{~mL}, 10 \mathrm{~mL}$ t.i.d. p.o. for patients) with standard prednisone treatment alone $(n=64)$ in children and adults (aged 13.5-45 years old) and followed them for 1 year. The study only reported infection times in 1 year (intervention group: $2.57 \pm 0.63$ times/year versus control group: $5.32 \pm 1.31$ times/year) and did not describe the URTI rate.

We also identified two Cochrane reviews related to Astragalus and intervention for preventing infection in nephrotic syndrome. Yuan et al's review [16] covered three studies ( $n=28)$ : one [21] reported that Huangqi and red Chinese date reduced some adverse reactions (Cushing's syndrome: RR $0.55,95 \%$ CI $=0.32-0.94$; hormone withdrawal syndrome (HWS): RR $0.58,95 \% \mathrm{CI}=0.39-0.85$; respiratory tract infection: RR $0.27,95 \% \mathrm{CI}=0.08-0.88)$. Wu et al.'s review [14] included 12 studies conducted in China that included 762 children with nephrotic syndrome. With four positive interventions, that is, intravenous immune globulin (IVIG), Bacillus Calmette-Guerin (BCG), Astragalus, and TIAOJINING, two studies [17, 18] reported that Astragalus granules showed a significantly beneficial effect (RR 0.62, 95\% 
TABLE 4: Quality assessment of the included studies.

\begin{tabular}{|c|c|c|c|c|c|c|}
\hline & $\begin{array}{l}\text { Concealment of } \\
\text { allocation }\end{array}$ & $\begin{array}{c}\text { Randomization } \\
\text { sequence } \\
\text { generation }\end{array}$ & Blinding & Selective reporting & $\begin{array}{l}\text { Intention-to-treat } \\
\text { analysis }\end{array}$ & $\begin{array}{l}\text { Level of } \\
\text { evidence }\end{array}$ \\
\hline Kang, 2005 [17] & NS & Unclear $^{1}$ & No & Not mentioned & Not mention & Unclear risk \\
\hline $\begin{array}{l}\text { J. Chen and S. Q. } \\
\text { Chen, } 2008 \text { [18] }\end{array}$ & NS & $\begin{array}{c}\text { Quasi- } \\
\text { randomization }\end{array}$ & No information & Not mentioned & Not mention & Unclear risk \\
\hline
\end{tabular}

${ }^{1}$ The study did not provide the information on the method of random sequence generation and only presented the data that participants with nephrotic syndrome were randomly allocated to treatment and control groups.

${ }^{2}$ The patients with nephrotic syndrome were allocated to the treatment and control groups according to the order of admission.

$\mathrm{CI}=0.47-0.83)$ in reducing the risk of infection in children with nephrotic syndrome. However, neither study specifically reported the respiratory infection rate.

We did not include J. Zhang and Y. Zhang (2008) [20] or Xie and Peng (2010) [19] because the populations they studied contained not only children. We also did not include Yuan et al. (2004) [21], even though it was the only study that reported the URTI rate, because the study included both children and adults. When we tried to contact the authors to get the number of children (aged below 18) with URTI, we received no response.

We managed to get the URTI rate in the two remaining studies $[17,18]$ by contacting the authors by telephone or email. Thus, only J. Chen and S. Q. Chen (2008) [18] and Kang (2005) [17] were included in our further evaluation and analysis. The characteristics of the included studies are summarized in Tables 2 and 3.

4.2. Quality of Evidence. The quality of methods and reporting of results in the remaining five articles were appraised critically for quality of methodology, design, and data analysis using GRADE. The quality of these studies was low (Table 5). All the studies included were unclear in terms of risk of bias; the papers did not provide bias information regarding the study design. Thus, we assumed that the potential limitations were likely to lower the confidence in estimation of effects. No study reported information about the randomization sequence generation or blinding (Table 4). The RR for Huangqi intervention versus conventional treatment alone was $0.56(95 \% \mathrm{CI}=0.33-0.93 ; P=0.10$; Table 5$)$.

\section{Application of Evidence and Followup}

According to the two studies included $[17,18]$ and the experience of Professor Huang Chunlin, we administered Astragalus granules (the Astragalus was from Shanxi Province, China). The origin of the herb was authenticated, and the material was examined for microorganisms, heavy metals, and pesticides, according to accepted standards (good manufacturing practices, GMP) in China. The Astragalus was found to be of good quality, and the crude Astragalus had been extracted by TianJiang Pharmaceutical Co. Ltd., China. The Astragalus was extracted at a ratio of $1.5 \mathrm{~g}$ from $10 \mathrm{~g}$ of crude Astragalus. Freeze-dried extracts of Astragalus were analyzed by high-performance liquid chromatography using Astragaloside IV as an active component.
The patient was administered $2.25 \mathrm{~g}$ Astragalus granules (equivalent to $15 \mathrm{~g}$ crude Astragalus) twice/day for 2 years. During the Astragalus granule treatment period, prednisone was tapered gradually (prednisone taper, $2.5 \mathrm{mg} / \mathrm{month}$ ). When the patient had URTI, he was asked to stop taking Huangqi granules and to maintain his prednisone dosage. After 3 months of Astragalus granule treatment, he felt less fatigued and sweaty, and his serum immunoglobulin $G$ reached normal levels. During the maintenance period on prednisone $(10 \mathrm{mg} / \mathrm{d})$, he suffered from URTI once, and this was alleviated in 3 days without relapse of NS. He had URTI twice; his symptoms were mild and lasted for no more than 7 days, without relapse of NS, 1 year after the cessation of prednisone. To date, he has had a total of three episodes of URTI in 2 years, compared with 8 times per year before Astragalus treatment, and no relapse of NS, compared with three relapses in 1 year before Astragalus treatment.

\section{Discussion}

6.1. Mechanism of Astragalus in Preventing URTI. Before 1940 , mortality in children with nephrotic syndrome reached $40 \%$, due, mainly, to infections [22]. Although mortality declined dramatically after the introduction of glucocorticoids and antibiotics, infections remained the major cause of death in children with nephrotic syndrome $[23,24]$. The severe infections leading to death included sepsis, peritonitis, and pneumonia [25]. Acute URTI may not threaten the lives of nephrotic syndrome patients; however, it may be associated with relapse and acute exacerbation of nephrotic syndrome [5]. Its mechanism(s) involve the following aspects: (1) a decrease in immunoglobulins [26], (2) dysfunction in specific antibody production [27], (3) decreases in complement bypass factors $B$ and $D[28,29]$, and (4) immunosuppressive therapies.

Astragalus has been shown to be able to correct the problems causing susceptibility to URTI in nephrotic patients. For example, Astragalus decreased soluble IL-2 receptor (SIL-2R) and IL-8 levels, while increasing IgA, IgM, and IgG levels in patients suffering from recurrent URTI [30]. Experimental studies found that oral administration of an Astragalus formulation (Bu-Zhong-Yi-Qi-Tang, $100 \mathrm{mg} / \mathrm{kg}$ per day) to young BALB/c mice enhanced influenza virusspecific IgA antibody titers significantly in the nasal cavity. This may be one of the mechanisms by which Astragalus and its formulations reduce influenza virus infection [31]. 


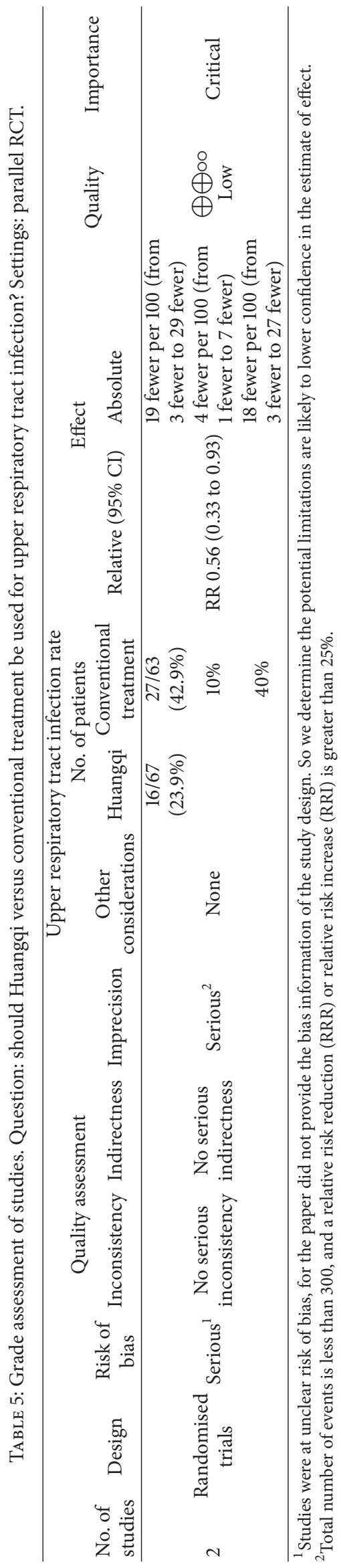


Astragalus was also found to reduce overinhibition by immunosuppressants. In vitro studies showed that Astragalus reversed the inhibition of cyclophosphamide on T lymphocytes in experimental rats [32, 33]. In China, Astragalus and its formulations have been used widely in patients on immunosuppressive treatment. Astragalus inhibits common viruses, such as coxsackievirus [34] and influenza virus, and common bacteria, such as nonhemolytic streptococcus, pneumococcus, and Staphylococcus aureus [35], that can cause upper respiratory tract infections.

Based on these findings, Astragalus would seem to have a good biological basis for use in preventing URTI in nephrotic patients.

6.2. Evidence-Based Clinical Practice. According to the GRADE method of bias evaluation, there were potentially large biases in the included studies, which could have had an impact on the outcome. For example, there was no description of adequate sequence generation, allocation concealment, or blinding, which could have produced bias in selection, implementation, and measurement. All eligible studies were carried out in China and published in Chinese; thus, positive results were more likely to have been reported than negative results [36]. For these reasons, the risk of bias in these trials was potentially serious, and the level of evidence by GRADEpro was low.

Although the level of evidence for using Astragalus with the patient was low, we had the aid of the GRADE instruments to make the clinical decision. First, the GRADE tools consider the recommendation strength, reflecting how well we could determine whether the intervention would do more good than harm [37]. The benefits of intervention include lowering morbidity and mortality, improving the quality of life, and reducing medical burden, whereas the disadvantages are the opposite outcomes. Our study found that Radix Astragali plus prednisone could significantly reduce the incidence of URTI in children with nephrotic syndrome compared with prednisone treatment alone, while having no side effects in most cases.

Second, because each treatment has its own advantages and disadvantages, it is important for doctors to make clinical decisions by evaluating benefit, risk, and convenience from the patient's point of view [38]. The patient and his relatives obtained relevant information on the Internet about the ability of Radix Astragali to reduce respiratory infection, which was confirmed by its use in other patients, so they were eager for the patient to have Radix Astragali treatment, and they wanted to know about the direction and course of treatment.

Finally, another key factor in clinical decision making is the cost. The possibility of a strong recommendation for a very good treatment can be reduced because of its high cost and unavailability. Thus, one of the crucial factors in recommendation strength is evidence regarding the conditions and demands of its practical use [39]. Astragalus therapy is much cheaper than other methods commonly used in China to prevent URTI in nephrotic syndrome, such as injections of gamma globulin or thymosins. Thus, it can be used with the vast majority of patients with nephrotic syndrome.
To summarize, we decided to administer Radix Astragali to the patient to prevent URTI, and the dose and course were referred to an expert for an opinion. According to Professor Huang's experience of syndrome differentiation in Chinese medicine (CM), the outstanding symptoms of the boy were fatigue, hidrosis, and being prone to suffer from upper respiratory tract infection, indicating a lung Qi deficiency. Astragalus membranaceus was the right herbal medicine for this syndrome. From the perspective of modern medicine, the serum IgG of the patient was slightly low, showing a decline in humoral immune function, and this may have been related to the frequent occurrence of upper respiratory tract infections. Astragalus can improve immune function and enhance the serum level of IgG. Thus, the use of Astragalus in the patient could prevent the relapse of NS through reducing the incidence of upper respiratory tract infection. The dose and duration of Astragalus treatment for the patient were determined from reports of clinical trials and the experience of Professor Huang. The Astragalus granules were from a pharmaceutical company that was GMP compliant. They were administered to the patient, while prednisone was slowly tapered, though maintained for a long enough time. When an upper respiratory tract infection occurred, manifested as a sore throat and fever, the Astragalus granules were stopped temporarily and then restarted when the infection was controlled and the symptoms disappeared. After 3 months of therapy, the syndrome of lung Qi deficiency in the patient was obviously improved, and the serum IgG returned to normal levels. In the 2year period of prednisone maintenance and discontinuance after administration of Astragalus, his incidence of upper respiratory tract infection was diminished significantly (1.5 times per year versus eight times per year), and there was no relapse of NS.

\section{Conflict of Interests}

The authors declare that they have no conflict of interests and no relationship of interest with any drug manufacturer. There is no financial gain from using the drugs mentioned in this paper. The case presentation was approved by the patient and his parents.

\section{Authors' Contribution}

C. Zou and G. Su contributed equally to the work and should be regarded as cofirst authors.

\section{Acknowledgments}

This work was supported by the Construction Project in 2011 from the Research Studio of Famous Old TCM Practitioners Experience Heritage, State Administration of Traditional Chinese Medicine (no. 2012KT1301), and Research Project for Practice Development of National TCM Clinical Research Bases. 


\section{References}

[1] P. McIntyre and J. C. Craig, "Prevention of serious bacterial infection in children with nephrotic syndrome," Journal of Paediatrics and Child Health, vol. 34, no. 4, pp. 314-317, 1998.

[2] P. F. Du, S. R. Zhu, and G. P. Wang, "An analysis for nosocomial infection in primary nephrotic syndrome-a report of 125 cases," Chinese Journal of Clinical Pediatrics, vol. 14, no. 1, pp. 35-36, 1996.

[3] Q. Y. Wu and X. Wu, "Clinical study of gammaglobulin on upper respiratory infection prevention in nephrotic syndrome children," Journal of Hainan Medical College, vol. 15, no. 8, pp. 879-880, 2009.

[4] B. Wu and N. F. Xu, "Clinical epidemiology study on risk factors for nosocomial infection in children with nephrotic syndrome," Chinese Journal of Nosocomiology, vol. 10, no. 3, pp. 34-35, 2000.

[5] N. E. MacDonald, N. Wolfish, P. McLaine, P. Phipps, and E. Rossier, "Role of respiratory viruses in exacerbations of primary nephrotic syndrome," Journal of Pediatrics, vol. 108, no. 3, pp. 378-382, 1986.

[6] A. A. S. L. Safaei and S. Maleknejad, "Clinical and laboratory findings and therapeutic responses in children with nephrotic syndrome," Indian Journal of Nephrology, vol. 20, no. 2, pp. 6871, 2010.

[7] A. Sumboonnanonda, N. Chongchate, V. Suntornpoch, A. Pattaragarn, and S. Supavekin, "Difficult-to-treat nephrotic syndrome: management and outcome," Journal of the Medical Association of Thailand, vol. 88, supplement 8, pp. S142-S148, 2005.

[8] R. K. Alwadhi, J. L. Mathew, and B. Rath, "Clinical profile of children with nephrotic syndrome not on glucorticoid therapy, but presenting with infection," Journal of Paediatrics and Child Health, vol. 40, no. 1-2, pp. 28-32, 2004.

[9] A. Gulati, A. Sinha, V. Sreenivas, A. Math, P. Hari, and A. Bagga, "Daily corticosteroids reduce infection-associated relapses in frequently relapsing nephrotic syndrome: a randomized controlled trial," Clinical Journal of the American Society of Nephrology, vol. 6, no. 1, pp. 63-69, 2011.

[10] A. S. Abeyagunawardena and R. S. Trompeter, "Increasing the dose of prednisolone during viral infections reduces the risk of relapse in nephrotic syndrome: a randomised controlled trial," Archives of Disease in Childhood, vol. 93, no. 3, pp. 226-228, 2008.

[11] J. Wu, Z. Wang, and D. Wang, "Respiratory virus expression in renal tissues and urine of children with steroid responsive simple nephrotic syndrome," Journal of Sichuan University (Medical Science Edition), vol. 38, no. 6, pp. 969-972, 2007.

[12] A. A. Eddy and J. M. Symons, "Nephrotic syndrome in childhood," The Lancet, vol. 362, no. 9384, pp. 629-639, 2003.

[13] A. Shroff, R. Frank, M. Vergara, B. Gauthier, and H. Trachtman, "Prevention of serious bacterial infections in new-onset nephrotic syndrome: a survey of current practices," Clinical Pediatrics, vol. 41, no. 1, pp. 47-49, 2002.

[14] H. M. Wu, J. L. Tang, L. Cao, Z. H. Sha, and Y. Li, "Interventions for preventing infection in nephrotic syndrome," Cochrane Database of Systematic Reviews, no. 4, Article ID CD003964, 2012.

[15] K. I. Block and M. N. Mead, "Immune system effects of echinacea, ginseng, and astragalus: a review," Integrative Cancer Therapies, vol. 2, no. 3, pp. 247-267, 2003.

[16] W. Yuan, J. Wang, and T. Wu, "Chinese herbal medicine Huangqi type formulations for nephrotic syndrome," Cochrane
Database of Systematic Reviews, no. 2, Article ID CD006335, 2008.

[17] G. G. Kang, "Preventive effects of Huangqi on secondary infection in children with simple nephrotic syndrome," Chinese Journal of Integrated Traditional and Western Nephrology, vol. 6, no. 12, pp. 718-719, 2005.

[18] J. Chen and S. Q. Chen, "Preventive effects of Huangqi on infection in children with nephrotic syndrome," Chinese Journal of Integrated Traditional and Western Medicine, vol. 28, no. 5, pp. 467-469, 2008.

[19] X. L. Xie and Y. Peng, "Preventive effect of Huangqi in refractory infection of nephrotic syndrome," Hubei Journal of Traditional Chinese Medicine, vol. 32, no. 05, pp. 9-10, 2010.

[20] J. Zhang and Y. Zhang, "Treatment effects of Huangqi granules on nephrotic syndrome and its secondary infection," Chinese Journal of Traditional Chinese Medicine, vol. 23, no. 09, pp. 846$847,2008$.

[21] H. Z. Yuan, F. Xie, and C. T. Zhang, "The effect of Huangqi and red Chinese date in the process of corticosterone reduction in refractory primary nephrotic syndrome with mesangial proliferative glomerulonephritis," Chinese Journal of Integrated Medicine, vol. 5, no. 7, pp. 413-414, 2004.

[22] L. A. Barness, G. H. Moll, and C. A. Janeway, "Nephrotic syndrome I. Natural history of the disease," Pediatrics, vol. 5, no. 3, pp. 486-503, 1950.

[23] D. Lawson, A. Moncrieff, and W. W. Payne, "Forty years of nephrosis in childhood," Archives of disease in childhood, vol. 35, pp. 115-126, 1960.

[24] G. Arneil, "164 children with nephrosis," The Lancet, vol. 278, no. 7212, pp. 1103-1110, 1961.

[25] "Minimal change nephrotic syndrome in children: deaths during the first 5 to 15 years' observation. Report of the international study of kidney disease in children," Pediatrics, vol. 73, no. 4, pp. 497-501, 1984.

[26] J. Giangiacomo, T. G. Cleary, and B. R. Cole, "Serum immunoglobulins in the nephrotic syndrome. A possible cause of minimal change nephrotic syndrome," The New England Journal of Medicine, vol. 293, no. 1, pp. 8-12, 1975.

[27] J. S. Spika, N. A. Halsey, A. J. Fish et al., "Serum antibody response to pneumococcal vaccine in children with nephrotic syndrome," Pediatrics, vol. 69, no. 2, pp. 219-223, 1982.

[28] R. H. McLean, A. Forsgren, B. Björkstén, Y. Kim, P. G. Quie, and A. F. Michael, "Decreased serum factor B concentration associated with decreased opsonization of Escherichia coli in the idiopathic nephrotic syndrome," Pediatric Research, vol. 11, no. 8, pp. 910-916, 1977.

[29] M. Ballow, T. L. Kennedy, K. M. Gaudio, N. J. Siegel, and R. H. McLean, "Serum hemolytic factor D values in children with steroid-responsive idiopathic nephrotic syndrome," Journal of Pediatrics, vol. 100, no. 2, pp. 192-196, 1982.

[30] Q. F. Nie and P. Yi, "Huangqi on SIL-2R, IL-8 and Ig in refractory respiratory infection patients," Journal of Cellular and Molecular Immunology, vol. 4, pp. 362-363, 2009.

[31] H. Kiyohara, T. Nagai, K. Munakata et al., "Stimulating effect of Japanese herbal (Kampo) medicine, Hochuekkito on upper respiratory mucosal immune system," Evidence-Based Complementary and Alternative Medicine, vol. 3, no. 4, pp. 459-467, 2006.

[32] D. T. Chu, W. L. Wong, and G. M. Mavligit, "Immunotherapy with Chinese medicinal herbs. II. Reversal of cyclophosphamide-induced immune suppression by administration of 
fractionated Astragalus membranaceus in vivo," Journal of Clinical and Laboratory Immunology, vol. 25, no. 3, pp. 125-129, 1988.

[33] K. S. Zhao, C. Mancini, and G. Doria, "Enhancement of the immune response in mice by Astragalus membranaceus extracts," Immunopharmacology, vol. 20, no. 3, pp. 225-233, 1990.

[34] T. Peng, Y. Yang, H. Riesemann, and R. Kandolf, "The inhibitory effect of Astragalus membranaceus on coxackie B-3 virus RNA replication," Chinese Medical Sciences Journal, vol. 10, no. 3, pp. 146-150, 1995.

[35] A. L. Miller, "Botanical influences on cardiovascular disease," Alternative Medicine Review, vol. 3, no. 6, pp. 422-431, 1998.

[36] J. L. Tang, S. Y. Zhan, and E. Ernst, "Review of randomised controlled trials of traditional Chinese medicine," The British Medical Journal, vol. 318, no. 7203, pp. 160-161, 1999.

[37] J. Thornton, P. Alderson, T. Tan et al., "Introducing GRADE across the NICE clinical guideline program," Journal of Clinical Epidemiology, vol. 66, no. 2, pp. 124-131, 2013.

[38] G. H. Guyatt, A. D. Oxman, R. Kunz et al., "GRADE: going from evidence to recommendations," The British Medical Journal, vol. 336, no. 7652, pp. 1049-1051, 2008.

[39] M. Brunetti, I. Shemilt, S. Pregno et al., "Grade guidelines: 10. Considering resource use and rating the quality of economic evidence," Journal of Clinical Epidemiology, vol. 66, no. 2, pp. 140-150, 2013. 


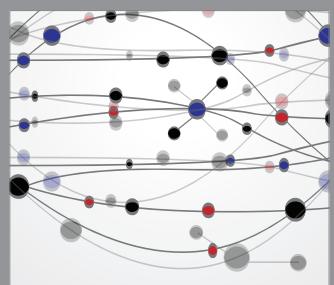

The Scientific World Journal
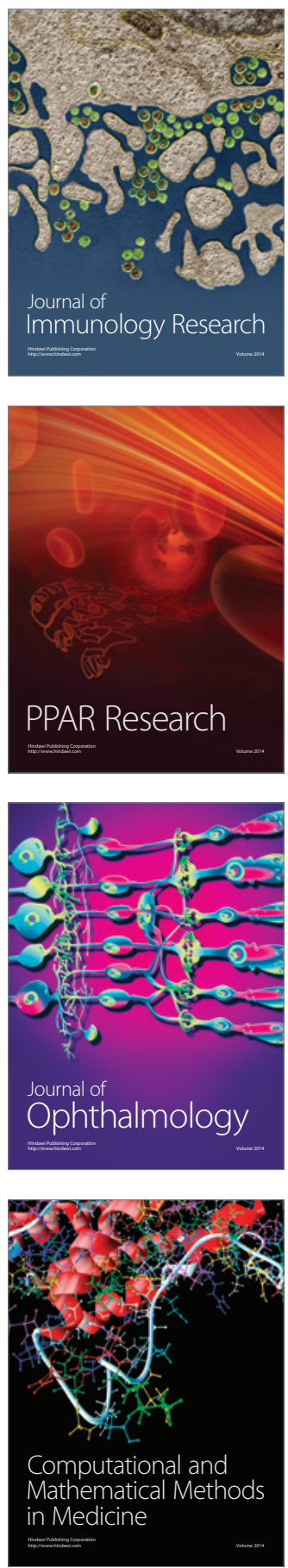

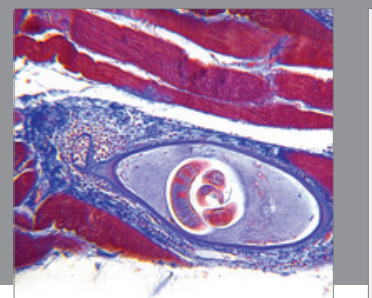

Gastroenterology

Research and Practice
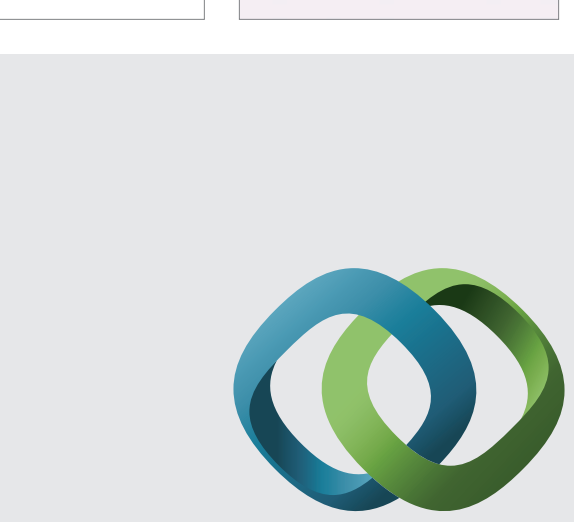

\section{Hindawi}

Submit your manuscripts at

http://www.hindawi.com
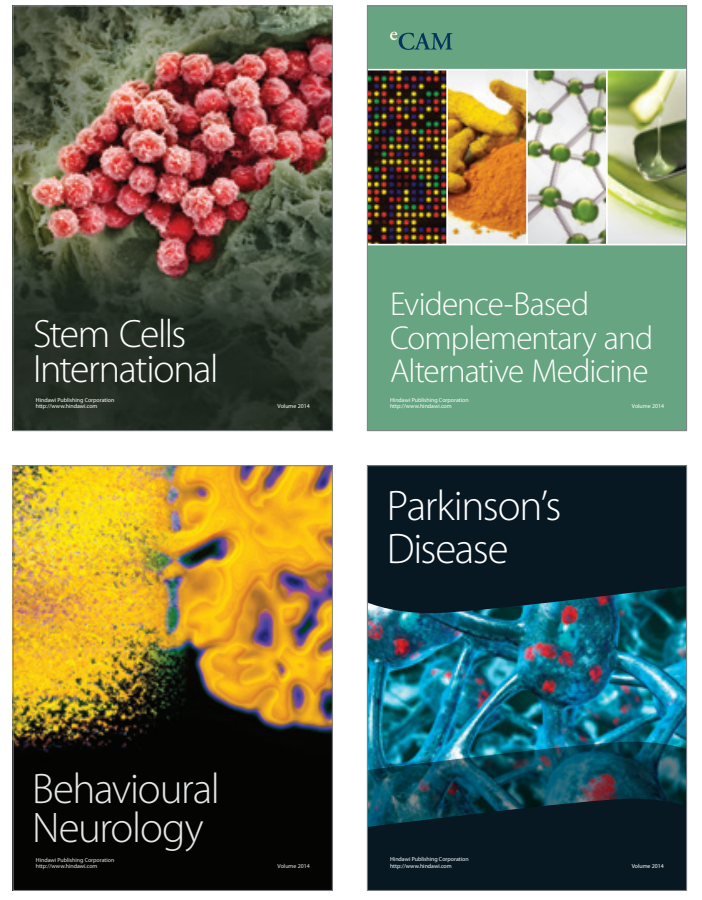
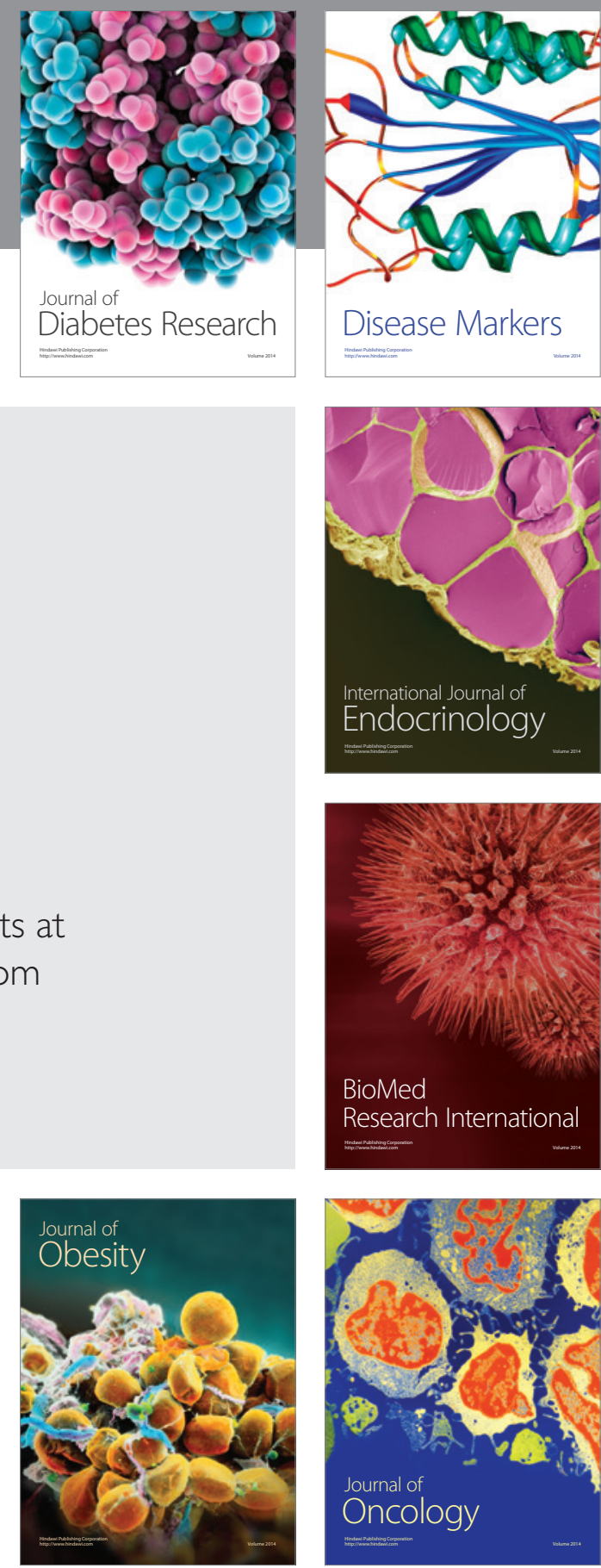

Disease Markers
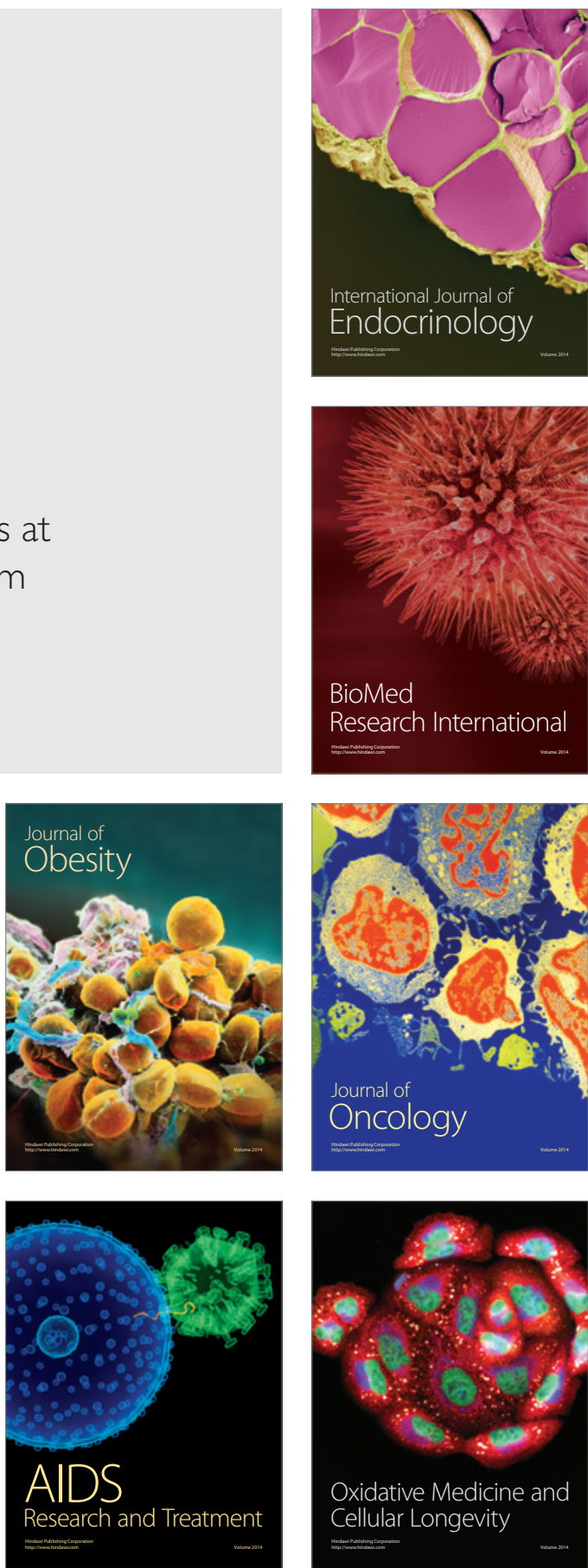